\title{
Influência de agregados reciclados de concreto nas propriedades de novos concretos
}

\author{
Influence of recycled concrete aggregates in properties of new concretes \\ Influencia de los áridos de hormigón reciclado en las propiedades de los nuevos hormigones
}

Recebido: 24/03/2021 | Revisado: 30/03/2021 | Aceito: 02/04/2021 | Publicado: 12/04/2021

\author{
Leandro Martins \\ ORCID: https://orcid.org/0000-0001-8034-4679 \\ Universidade Federal do Pará, Brasil \\ E-mail: leandro07hsm@gmail.com \\ Luciana de Nazaré Pinheiro Cordeiro \\ ORCID: https://orcid.org/0000-0001-7931-4042 \\ Universidade Federal do Pará, Brasil \\ E-mail: lupcordeiroo@gmail.com \\ Isaura Nazaré Lobato Paes \\ ORCID: https://orcid.org/0000-0003-1781-1689 \\ Universidade Federal do Pará, Brasil \\ E-mail: isaurapaes@ufpa.br \\ Paulo Sérgio Lima Souza \\ ORCID: https://orcid.org/0000-0002-0328-7655 \\ Universidade Federal do Pará, Brasil \\ E-mail: paseliso@ufpa.br \\ Arthur Aviz Palma e Silva \\ ORCID: https://orcid.org/0000-0001-5686-5984 \\ Universidade de Brasília, Brasil \\ E-maileng.aviz@gmail.com
}

\begin{abstract}
Resumo
Este artigo apresenta os resultados de um estudo de laboratório sobre as propriedades do concreto com substituição parcial de agregado graúdo reciclado de concreto e incorporação de adições minerais, sílica ativa e o metacaulim, comercialmente disponíveis na região. Os ensaios realizados foram resistência à compressão axial, módulo de elasticidade e absorção de água por capilaridade, todos na idade de 28 dias. Os resultados mostraram que a adição de sílica ativa, melhora as propriedades dos concretos com resíduo. A sílica ativa preencheu os vazios presentes no agregado, densificando a microestrutura desse compósito. No que diz respeito ao metacaulim, apesar dos resultados serem satisfatórios, não houve variabilidade estatística quando este foi comparado com o concreto sem adição. Acreditase que esse material seria mais eficiente se avaliado em idades mais avançadas. Pode-se concluir pelas características encontradas que o concreto com substituição parcial de 50\% de agregado graúdo reciclado de concreto e a adição de sílica apresentam viabilidade técnicas para a aplicação em elementos com função estrutural.
\end{abstract}

Palavras-chave: Agregado graúdo reciclado de concreto; Sílica ativa; Metacaulim; Propriedades mecânicas.

\begin{abstract}
This paper presents the results of a laboratory study of the properties of concrete with partial substitution of recycled coarse aggregate concrete and incorporating mineral additions, silica fume and metakaolin, commercially available in the region. The tests were compressive strength and modulus of elasticity in age of 28 days. The results showed that the silica fume addition improves the properties of concrete to the residue. Silica fume filled the voids present in the aggregate, the microstructure densifies of this composite. The regards the addition of metakaolin, although the results were satisfactory, there were no statistical variability when it was compared to concrete without the addition. It is believed that this material would be more efficient at older ages. It can be concluded that the characteristics found by the concrete with partial substitution of 50\% recycled coarse aggregate concrete and adding silica techniques have potential for use in structural elements function.
\end{abstract}

Keywords: Recycled coarse aggregate concrete; Silica fume; Metakaolin; Physical properties.

\section{Resumen}

Este artículo presenta los resultados de un estudio de laboratorio sobre las propiedades del hormigón con reposición parcial de áridos de hormigón reciclado e incorporación de adiciones minerales, humo de sílice y metacaolín, disponibles comercialmente en la región. Los ensayos realizados fueron de resistencia a la compresión axial, módulo de elasticidad y absorción de agua por capilaridad, todos a la edad de 28 días. Los resultados mostraron que la adición de humo de sílice mejora las propiedades de los hormigones con residuo. La sílice activa llenó los vacíos presentes en el agregado, densificando la microestructura de este compuesto. Con respecto al metacaolín, a pesar de que los resultados fueron satisfactorios, no hubo variabilidad estadística al compararlo con el hormigón sin adición. Se cree que 
este material sería más eficaz si se evaluara a edades más avanzadas. Se puede concluir por las características encontradas que el hormigón con 50\% de reposición parcial de áridos de hormigón reciclado y la adición de sílice presentan viabilidad técnica para la aplicación en elementos con función estructural.

Palabras clave: Hormigón de agregado grueso reciclado; Humo de sílice; Metacaolín; Propiedades físicas.

\section{Introdução}

A sociedade moderna está cada vez mais preocupada com a proteção do meio ambiente. Para tal faz-se necessário satisfazer as necessidades presentes sem prejudicar as gerações futuras. A preocupação com o volume de resíduos sólidos gerados pela construção civil tem levado diversos países a estudar a possibilidade do seu reaproveitamento.

Na construção civil, o conceito de desenvolvimento sustentável constrói-se em torno de questões de desempenho. É errôneo projetar uma construção que em um curto período de tempo necessite de uma intervenção. Sendo assim, os materiais precisam ser duráveis e aptos a atender a finalidade para os quais foram desenvolvidos.

Neste sentido, quando se propõe em utilizar resíduos como substituto de um material natural, faz-se necessário o entendimento de seu comportamento mecânico e de durabilidade, para que o desempenho do produto final não seja comprometido.

Uma das alternativas de aproveitamento de resíduos de construção civil é através de sua transformação em agregados. E a viabilidade técnica de sua inserção em matrizes cimentícias já foi confirmada por pesquisadores como Leite (2001), Buttler (2003), Corinaldesi e Moriconi (2009), Werle (2010) e Cordeiro (2013). Porém, algumas medidas precisam ser tomadas, a fim de minimizar as deficiências de alguns resíduos.

É um consenso que o agregado reciclado de concreto é um material frágil, se comparado com o agregado natural. Porém, quando beneficiado adequadamente, misturado de maneira otimizada, e incorporado em conjunto com materiais que aumentam a eficiência do compósito podem ser utilizados em concretos para fins estruturais. Diversos pesquisadores vem apresentando concretos com agregados reciclados de concreto que poderiam ser aplicados em elementos estruturais, cita-se Radonjanin et al. (2013) que avaliaram a combinação de adições como sílica ativa, metacaulim, cinza volante e filler, em concretos com resíduos de concreto, ao final os referidos autores classificaram onde cada combinação poderia ser aplicada, alguns foram adequados para peças estruturais, outros para fabricação de artefatos de concreto.

Behera et al. (2014) apresentaram em sua pesquisa diferentes técnicas de processamento de agregado reciclado, visando a otimização do concreto produzido. Mohamed et al. (2012) e Tam e Tam (2008) constataram a eficiência da mistura em etapas para concretos com agregado graúdo reciclado de concreto (AGRC). Berndt (2009) demonstrou que o concreto com 100\% de AGRC pode ser melhorado através da incorporação de escória de alto forno. Silva et al. (2021) realizaram experimentos com substituição de cimento por cinza de casca de arroz (CCA) e agregados reciclados substituindo os agregados convencionais. Estes autores concluíram que alguns dos quesitos mais afetados com a utilização destes agregados são as propriedades de absorção e porosidade do material resultante.

Pode-se inferir através das revisões realizadas que existe uma preocupação em aproveitar o resíduo de construção civil em concretos com fins estruturais. Apesar das normas nacionais ainda não permitirem a sua utilização de agregados reciclados em peças com funções estruturais.

Diante dessas constatações esta pesquisa tem por objetivo principal avaliar o comportamento de concreto com substituição parcial de 50\% de agregado graúdo reciclado e adição de sílica ativa e metacaulim, visando sua aplicação em concretos estruturais. Acredita-se que a incorporação de adições minerais promove mudanças no comportamento do concreto com agregado graúdo reciclado de concreto, deixando em algumas situações com características similares às de um concreto confeccionado com agregado natural.

Foram realizadas cinco de mistura, que tinham como parâmetro fixo o teor de agregado graúdo reciclado de concreto 
$(50 \%)$, a relação água/cimento $(0,60)$ e o abatimento $(100 \pm 20) \mathrm{mm}$. Como fatores controláveis adotou-se o tipo de adição (metacaulim e sílica ativa) e o teor de adição $(0,5 \%$ e $10 \%$, respectivamente). E as variáveis de respostas foram resistência à compressão axial, módulo de elasticidade e absorção de água por capilaridade.

\section{Metodologia}

Neste trabalho realizou-se uma comparação entre o desempenho de concretos com agregados graúdos reciclados com e sem adições minerais. Este trabalho é de caráter laboratorial, com análises quantitativas que dão suporte às suas conclusões e objetivos (Koche, 2011). Os agregados reciclados foram utilizados em substituição a 50\% do agregado graúdo natural.

O cimento utilizado foi o cimento Portland de alta resistência inicial - CPV ARI, este cimento apresentou, aos 28 dias, uma resistência média de $50 \mathrm{MPa}$. A massa específica desse cimento foi de $3,07 \mathrm{~g} / \mathrm{cm}^{3}$ e determinada segundo a NBR NM 23 (ABNT, 2000). A sílica ativa e o metacaulim apresentam, respectivamente, massa específica de $2,19 \mathrm{~g} / \mathrm{cm}^{3} \mathrm{e} 2,56 \mathrm{~g} / \mathrm{cm}^{3}$.

$\mathrm{O}$ agregado miúdo empregado foi uma areia de origem quartzosa, extraída de curvões de rios, localizados na região metropolitana de Belém. As características físicas deste material podem ser visualizadas na Tabela 1.

Tabela 1. Caracterização do Agregado Miúdo Natural.

\begin{tabular}{lcc}
\hline & Amostras & \\
\cline { 2 - 3 } Abertura das Peneiras (mm) & Massa Retida $(\%)$ & Massa Retida Acumulada (\%) \\
\hline 4,80 & 0,4 & 1 \\
2,40 & 0,8 & 5 \\
1,20 & 3,4 & 22 \\
0,60 & 17,4 & 76 \\
0,30 & 53,6 & 98 \\
0,15 & 22,2 & 100 \\
Fundo & 2,2 & NBR NM 248 (ABNT, 2003) \\
\hline Módulo de Finura & $\mathbf{2 , 0 2}$ & NBR NM 248 (ABNT, 2003) \\
Dimensão Máxima Característica (mm) & $\mathbf{1 , 2 0}$ & NBR NM 52 (ABNT, 2009) \\
Massa Específica $\left(\mathbf{g} / \mathbf{c m}^{\mathbf{3}}\right)$ & $\mathbf{2 , 6 2}$ & NBR NM 45 (ABNT, 2006) \\
Massa Unitária $\left(\mathbf{g} / \mathbf{c m}^{\mathbf{3}}\right)$ & $\mathbf{1 , 4 4}$ & \\
\hline
\end{tabular}

Fonte: Autores (2021).

Nota-se pelo módulo de finura que o agregado miúdo se enquadra na zona utilizável inferior, que segundo a NBR 7211 $(A B N T, 2009)$ varia de 1,55 a 2,20, o que a caracteriza-o como uma areia fina.

O agregado graúdo natural (AGNAT), provém de uma rocha de origem granítica, os dados desse material encontramse na Tabela 2. 
Tabela 2. Caracterização do Agregado Graúdo Natural.

\begin{tabular}{|c|c|c|}
\hline \multirow[b]{2}{*}{ Abertura das Peneiras (mm) } & \multicolumn{2}{|l|}{ Amostras } \\
\hline & Massa Retida (\%) & Massa Retida Acumulada (\%) \\
\hline 25,0 & 0 & 0 \\
\hline 19,0 & 35 & 35 \\
\hline 9,5 & 44 & 79 \\
\hline 6,3 & 4 & 83 \\
\hline 4,8 & 0 & 83 \\
\hline 2,4 & 5 & 88 \\
\hline 1,2 & 12 & 100 \\
\hline 0,6 & 0 & 100 \\
\hline 0,3 & 0 & 100 \\
\hline 0,15 & 0 & 100 \\
\hline Fundo & 0 & 100 \\
\hline Módulo de Finura & 6,85 & NBR NM 248 (ABNT, 2003) \\
\hline Dimensão Máxima Característica (mm) & $25 \mathrm{~mm}$ & NBR NM 248 (ABNT, 2003) \\
\hline Massa Específica $\left(\mathrm{g} / \mathrm{cm}^{3}\right)$ & 2,65 & NBR NM 53 (ABNT, 2003) \\
\hline Massa Unitária $\left(\mathrm{g} / \mathrm{cm}^{3}\right)$ & $\mathbf{1 , 5 3}$ & NBR NM 45 (ABNT, 2006) \\
\hline
\end{tabular}

Fonte: Autores (2021).

O agregado graúdo reciclado de concreto (AGRC) foi produzido em laboratório, a partir da cominuição de corpos de prova de concreto de diâmetro de $10 \mathrm{~cm}$ x $20 \mathrm{~cm}$ de altura. A resistência média aos 28 dias dessas espécimes era de $30 \mathrm{MPa}$, optou-se por trabalhar com este resíduo, devido as propriedades e características dos materiais. O processo de beneficiamento consistia em britar os corpos de provas, em britadores do tipo mandíbulas, e posteriormente com o auxílio de um peneirador mecânico, separar o material passante na peneira de \# $25 \mathrm{~mm}$ e retido na peneira de abertura \# 4,8 mm. A separação e estocagem por frações granulométricas (retidas \# 19,0 mm; 12,5 mm; 9,5 mm e 6,3 mm), era feita após a lavagem e secagem do resíduo. Os dados desse material encontram-se na Tabela 3.

Tabela 3. Caracterização do Agregado Graúdo Reciclado de Concreto.

\begin{tabular}{|c|c|c|}
\hline \multirow[b]{2}{*}{ Abertura das Peneiras (mm) } & \multicolumn{2}{|l|}{ Amostras } \\
\hline & Massa Retida (\%) & Massa Retida Acumulada (\%) \\
\hline 25,0 & 0 & 0 \\
\hline 19,0 & 25 & 25 \\
\hline 12,5 & 25 & 50 \\
\hline 9,5 & 25 & 75 \\
\hline 6,3 & 25 & 100 \\
\hline 4,8 & 0 & 100 \\
\hline 2,4 & 0 & 100 \\
\hline 1,2 & 0 & 100 \\
\hline 0,6 & 0 & 100 \\
\hline 0,3 & 0 & 100 \\
\hline 0,15 & 0 & 100 \\
\hline Módulo de Finura & 7,00 & NBR NM 248 (ABNT, 2003) \\
\hline Dimensão Máxima Característica (mm) & $25 \mathrm{~mm}$ & NBR NM 248 (ABNT, 2003) \\
\hline Massa Específica $\left(\mathrm{g} / \mathrm{cm}^{3}\right)$ & 2,53 & MÉTODO LEITE (2001) \\
\hline Massa Unitária $\left(\mathrm{g} / \mathrm{cm}^{3}\right)$ & 1,24 & NBR NM 45 (ABNT, 2006) \\
\hline Absorção de Água (\%) & 5,2 & LEITE MODIFICADO (2011) \\
\hline
\end{tabular}

Fonte: Autores (2021).

$\mathrm{O}$ aditivo utilizado foi o superplastificante à base de policarboxilato cuja densidade é de 1,08 $\pm 0,02 \mathrm{~kg} / \mathrm{l}$ e o pH é 5,0 1,0 . 


\subsection{Dosagem dos concretos com agregados graúdos reciclados}

O concreto foi dosado segundo o método proposto por Helene e Terzian (1993), adotando-se um teor de argamassa de $51 \%$ e fixando-se o abatimento em $(100 \pm 20) \mathrm{mm}$. As misturas foram realizadas em uma betoneira de eixo inclinado com capacidade de 120 litros. Estabeleceu-se como referência a resistência de $30 \mathrm{MPa}$, na idade de 28 dias, para o concreto com substituição de 50\% de AGRC. A Figura 1 apresenta a curva obtida durante o estudo de dosagem.

Figura 1. Dosagem do concreto com 50\% AGRC (Teor de argamassa de 51\%).

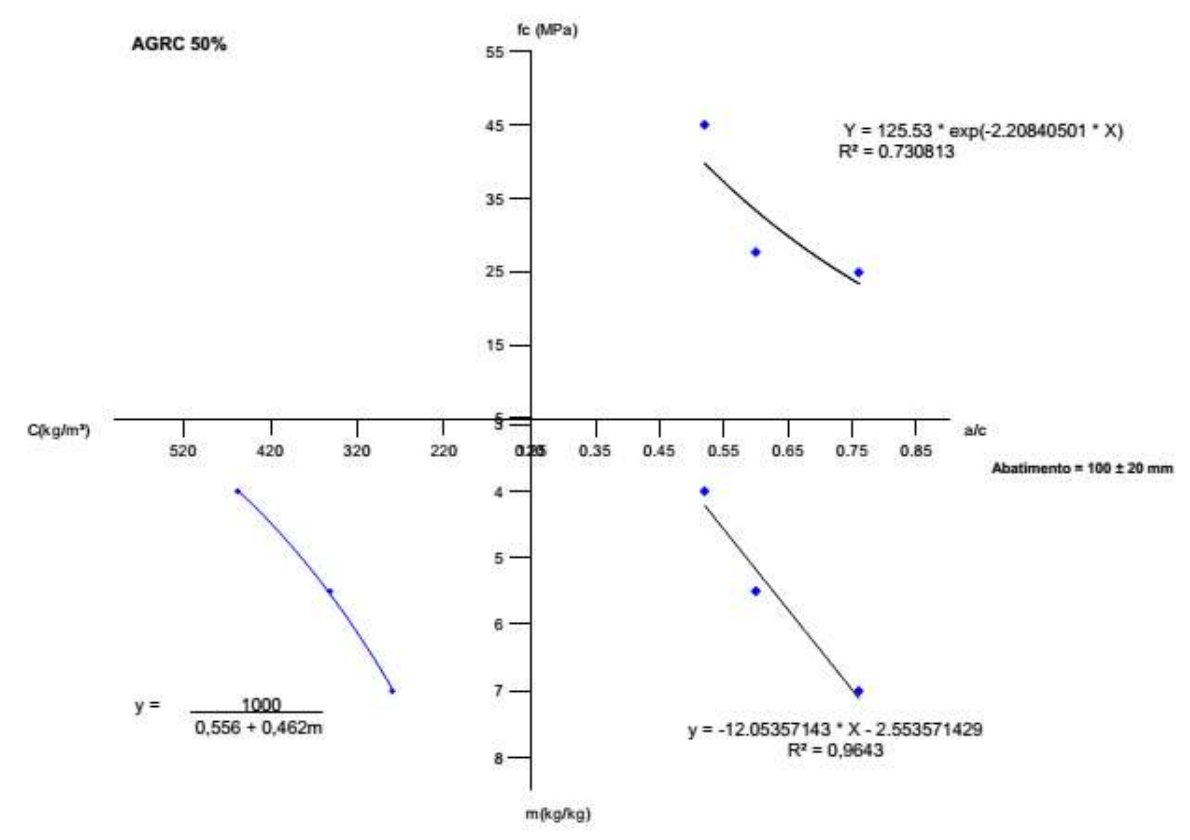

Fonte: Autores (2021).

A substituição do agregado natural por agregado reciclado foi realizada segundo o critério de compensação de volume, na equação 1 tem-se a formulação.

$M_{A R C}=\frac{M_{A N}}{\gamma_{A N}} x \gamma_{A R C}$

Equação 1

Onde:

$\mathrm{M}_{\mathrm{ARC}}=$ massa do agregado reciclado

$\mathrm{M}_{\mathrm{AN}}=$ massa do agregado natural

$\gamma_{\mathrm{NA}}=$ massa específica do agregado natural; e

$\gamma_{\text {ARC }}=$ massa específica do agregado reciclado.

Assim como Cordeiro (2013) trabalhou-se com o agregado reciclado na condição saturada, adotando-se o teor de saturação como parâmetro. Para tal, o agregado reciclado foi imerso em água com 24 horas de antecedência, no dia da 
concretagem retirava-se o AGRC da água e colocava em uma peneira para secagem, até que se alcançasse a massa equivalente a um teor de saturação de $80 \%$. A água presente no interior do agregado era descontada da água de mistura.

Trabalhou-se com traço, em massa, de 1: 2,52: 3,38 (cimento: agregado miúdo: agregado graúdo) e uma relação a/c de 0,6 (valor correspondente a resistência de $30 \mathrm{MPa}$ ). Usou aditivo superplastificante para se obter o abatimento previamente estipulado.

Os aditivos minerais estudados foram a sílica ativa e o metacaulim que participaram como adições ao concreto com AGRC. Avaliou-se também qual seria o teor ótimo de adições, estudando os seguintes níveis 0, 5 e $10 \%$ para cada uma das adições. Na Tabela 4 estão os consumos de materiais utilizados.

Tabela 4. Consumo de Materiais.

\begin{tabular}{l|cccccccc}
\hline \multicolumn{1}{c|}{ Notação } & \multicolumn{7}{c}{ Consumo $\left(\mathbf{k g} / \mathbf{m}^{3}\right)$} \\
& Água & Cimento & Sílica Ativa & Metacaulim & Aditivo & Areia & AGNAT & AGRC \\
\hline AGRC 50 & 190,48 & 317,46 & 0 & 0 & 12,70 & 800,00 & 536,51 & 512,21 \\
AGRC 50 SA5 & 190,48 & 317,46 & 15,87 & 0 & 12,70 & 800,00 & 536,51 & 512,21 \\
AGRC 50 SA10 & 190,48 & 317,46 & 31,75 & 0 & 15,87 & 800,00 & 536,51 & 512,21 \\
AGRC 50 MT5 & 190,48 & 317,46 & 0 & 15,87 & 20,63 & 800,00 & 536,51 & 512,21 \\
AGRC 50 MT10 & 190,48 & 317,46 & 0 & 31,75 & 30,16 & 800,00 & 536,51 & 512,21 \\
\hline
\end{tabular}

Fonte: Autores (2021).

Os concretos foram moldados segundo a NBR 5738 (ABNT, 2015), para cada mistura foram moldados dez corpos de provas. Estes foram desmoldados após 24 horas e mantidos em cura submersa em tanques com solução saturada de hidróxido de cálcio a $(23 \pm 2)^{\circ} \mathrm{C}$ até a data de ensaio $\left(28^{\circ}\right.$ dia $)$.

Partindo da hipótese de que a adição mineral melhora o desempenho do concreto com agregado reciclado, realizou-se os seguintes ensaios: resistência à compressão axial (NBR 5739, ABNT 2007), módulo de elasticidade (NBR 8522, ABNT 2003) e absorção de água por capilaridade (NBR 9779, ABNT 2012). Dessa maneira, torna-se possível comparar o desempenho de concretos produzidos com agregados reciclados, com e sem adições minerais.

\section{Resultados e Discussão}

A Tabela 5 apresenta os resultados médios de resistência à compressão axial e módulo de elasticidade, na idade de 28 dias.

Tabela 5. Valores médios da resistência à compressão axial e módulo de elasticidade.

\begin{tabular}{l|cc}
\hline Notação & Resistência à Compressão axial (MPa) & Módulo de Elasticidade (GPa) \\
\hline AGRC 50 & $35,3 \pm 1,4$ & $26,4 \pm 1,3$ \\
\hline AGRC 50 SA5 & $41,5 \pm 0,7$ & $27,0 \pm 2,2$ \\
\hline AGRC 50 SA10 & $46,7 \pm 0,6$ & $22,7 \pm 0,7$ \\
\hline AGRC 50 MT5 & $35,7 \pm 2,9$ & $29,3 \pm 2,8$ \\
\hline AGRC 50 MT10 & $41,9 \pm 3,0$ & $25,8 \pm 2,7$ \\
\hline
\end{tabular}

Fonte: Autores (2021). 
Observa-se que há uma tendência ao aumento de resistência à compressão axial à medida que se incorpora adição mineral. Os concretos com $50 \%$ de agregados graúdos reciclado e adição de sílica ativa tiveram um aumento de até $25 \%$, enquanto que para os concretos reciclados com adição de metacaulim, o incremento foi de até $16 \%$.

Com intuito de investigar se existia diferença significativa entre as misturas realizou-se a análise de variância (ANOVA) com o teste de Tukey para as resistências à compressão verificadas nestes concretos, conforme exposto na Tabela 6.

Tabela 6. Estatística descritiva, ANOVA e teste Tukey da resistência à compressão axial.

\begin{tabular}{|c|c|c|c|c|c|}
\hline & SQ & GL & MQ & $\mathbf{F}$ & $\mathbf{p}$ \\
\hline Tipo de Mistura & 235,91 & 2 & 117,95 & 10,308 & 0,001170 \\
\hline Erro & 194,53 & 17 & 11,44 & & \\
\hline \multirow{4}{*}{ Teste Tukey } & Tipo de Mistura & \multicolumn{2}{|c|}{ Diferença entre as médias } & \multicolumn{2}{|c|}{ Teste Tukey $(p<0,05)$} \\
\hline & S/Adição e Metacaulim & \multicolumn{2}{|c|}{3,57} & \multicolumn{2}{|c|}{0,225973} \\
\hline & S/ Adição e Sílica Ativa & \multicolumn{2}{|c|}{8,86} & \multicolumn{2}{|c|}{0,001518} \\
\hline & Metacaulim e Sílica Ativa & \multicolumn{2}{|c|}{5,29} & \multicolumn{2}{|c|}{0,015978} \\
\hline
\end{tabular}

Fonte: Autores (2021).

Pode-se observar que há diferença significativa entre os concretos. As médias diferem entre si quando se compara os concretos sem adição mineral com os concretos com adição de sílica ativa; e os concretos com adição de metacaulim com o de sílica ativa. $\mathrm{O}$ fato da sílica ativa melhorar as propriedades do concreto já havia sido percebido por autores. Cita-se Limbachiya et al. (2012) que mostrou desempenho satisfatórios de concretos com agregados reciclados de concreto e substituição de até 30\% de sílica. Çakir (2014) observou incrementos de resistência para misturas com 100\% AGRC e 10\% de sílica. Segundo Neville (2016), os efeitos benéficos da sílica ativa não estão limitados apenas à sua reação pozolânica, mas também ao efeito físico decorrente da capacidade de as partículas extremamente finas se acomodarem na interface pasta de cimento e agregado, densificando esta zona frágil.

Para Kou et al. (2011) a melhoria dessas propriedades está associada a dois mecanismos: (1) parte das adição penetra nos poros do agregado reciclado, e na interface agregado e pasta densificando estas zonas; (2) as fraturas originalmente presentes nessas materiais, possivelmente, são preenchidas pelos produtos de hidratação melhorando sua microestrutura.

A Figura 2 apresenta a microscopia eletrônica de varredura do concreto reciclado com adição de sílica ativa.

Figura 2. Microestrutura do concreto com adição de sílica.
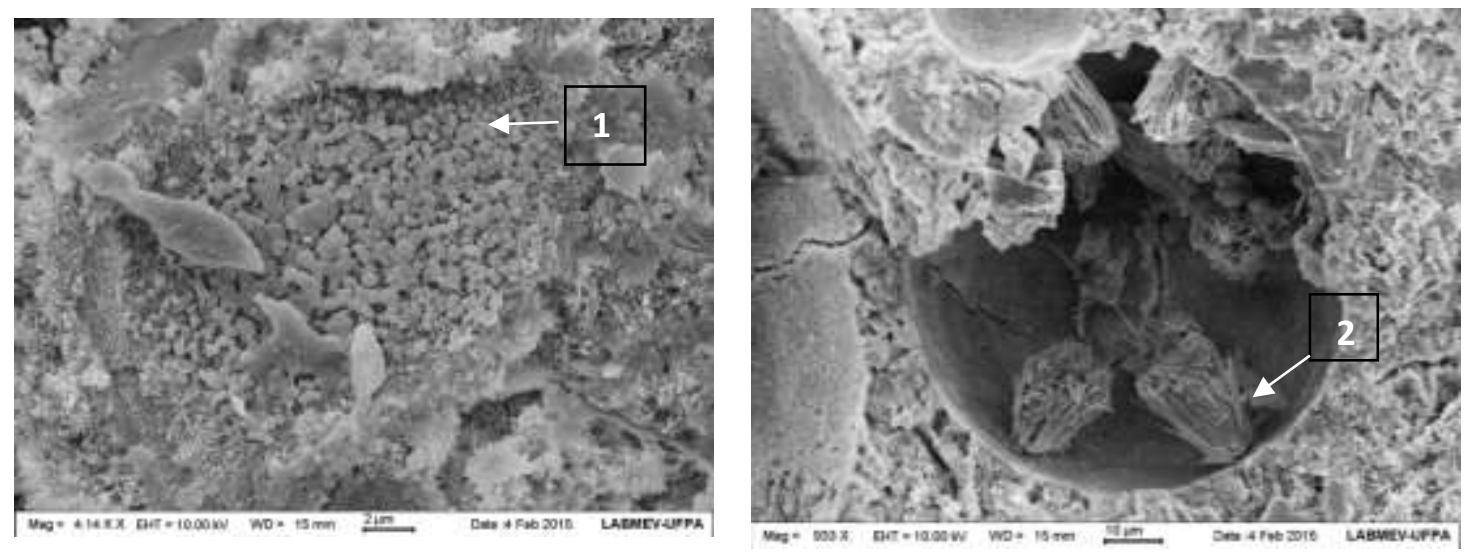

Fonte: Autores (2021). 
Observa-se pelas imagens a presença de sílica ativa nos poros dos agregados reciclados, conforme o descreveu Kou et al. (2011). No ponto 1, é possível identificar a sílica ativa agindo pelo efeito físico. Já no ponto 2, observa-se os produtos de hidratação preenchendo o vazio do agregado reciclado.

Para os concretos reciclados com adição de metacaulim, não observou-se diferença significativa, possivelmente os teores analisados não foram os ideais para este proporcionamento. Kou et al. (2011), por exemplo, só alcançou valores satisfatórios quando adicionou 15\% de metacaulim. Radonjanin et al. (2013), no entanto, teve resultados ótimos quando adicionou metacaulim e sílica ativa, em uma mesma mistura.

Em relação ao módulo de elasticidade cujos resultados encontram-se na Figura 2, percebe-se que em materiais heterogêneos e multifásicos como o concreto a fração volumétrica, a densidade e o módulo dos principais componentes são determinantes para o comportamento elástico do compósito (mehta \& Monteiro, 2014). Toma-se como um consenso que os concretos com agregados reciclados apresentam um módulo de elasticidade inferior, quando comparado com um concreto convencional. Este fator, encontra-se associado as características intrínseca dos agregados reciclados de concreto que apresentam uma porosidade decorrente da presença de argamassa. Os valores encontrados nessa pesquisa assemelham-se ao módulo de concreto com arenitos, calcários e cascalhos. Mehta e Monteiro (2014) cita que concretos com estes agregados apresentam valores de módulo que variam de 21 a $49 \mathrm{GPa}$. Acreditava-se que a presença das adições minerais melhorassem a matriz da pasta de cimento, e com isso incrementasse os valores de módulo de elasticidade, contudo esse comportamento a presença de adições não afetou significativamente no desempenho dessas misturas, vide Tabela 7.

Tabela 7. ANOVA do módulo de elasticidade.

\begin{tabular}{c|c|c|c|c|c}
\hline & SQ & GL & MQ & F & p \\
\hline Tipo de Mistura & 45,275 & 4 & 11,319 & 2,500 & 0,171114 \\
\hline Erro & 22,642 & 5 & 4,528 & & \\
\hline
\end{tabular}

Fonte: Autores (2021).

A respeito da absorção de água por capilaridade tem-se na Figura 3 os resultados obtidos nesta pesquisa.

Figura 3. Valores de absorção de água por capilaridade dos concretos reciclados.

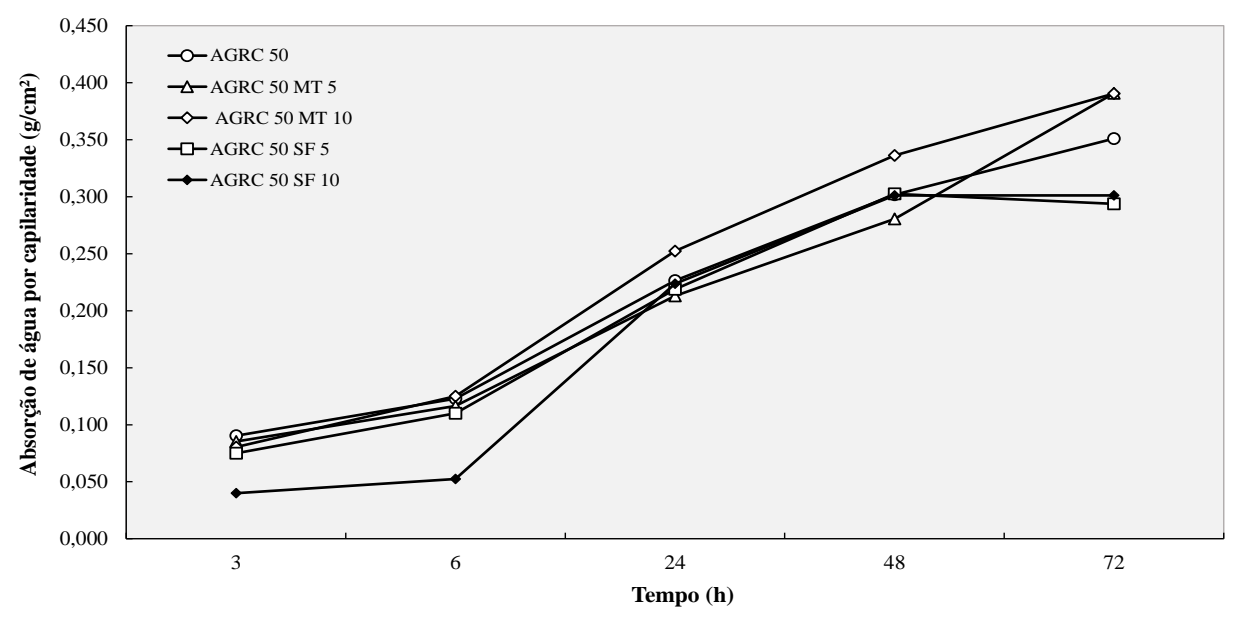

Fonte: Autores (2021). 
Os concretos produzidos com sílica ativa foram os que apresentaram os menores índices de absorção capilar de água o que denota uma maior densificação da matriz cimentícia. Este fato ocasiona uma dificuldade maior para que a água penetre e percole por seus poros, aumentando assim, a durabilidade dos concretos. Deve-se ressaltar, que com a substituição de $10 \%$ da referida adição, a absorção de água foi menor, em especial, nos momentos iniciais, equiparando-se ao valor de $5 \%$ de substituição, ao final do ensaio. Este resultado já era esperado, pois trabalhos de outros pesquisadores foram semelhantes ao deste estudo, como por exemplo, as pesquisas de Çakir (2014) e Dilbas et al. (2014) que obtiveram uma menor absorção de água em concretos com o uso de $100 \%$ de agregado graúdo reciclado e com adições minerais.

Já com relação ao uso do metacaulim este não apresentou desempenho satisfatório, em comparação com os resultados dos concretos com sílica ativa, sobretudo, nos momentos iniciais (percentual de 10\% de substituição), mensurando-se os maiores valores de absorção capilar de água. Isto pode ter ocorrido, devido esta adição ter gerado uma microestrutura com maior interligação de poros capilares e, assim, ocasionando um transporte de umidade mais intenso no interior das amostras. Este tipo de implicação, com relação ao uso do metacaulim, pode vir a ser um fator de restrição quando da analise de seu uso visando as melhores condições de durabilidade deste tipo de concreto.

\section{Conclusão}

Neste estudo avaliou-se as propriedades de concretos reciclados, com e sem adições de sílica ativa e metacaulim. Baseados nos resultados alcançados pode-se concluir que:

- Houve um aumento de resistência à compressão axial à medida que se incorporou as adições minerais. Os concretos com 50\% de agregados graúdos reciclado e adição de sílica ativa tiveram um aumento de até $25 \%$, enquanto que para os concretos reciclados com adição de metacaulim, o incremento foi de até $16 \%$.

- Os concretos com agregados reciclados apresentam um módulo de elasticidade inferior, quando comparado com um concreto convencional. Esta característica, encontra-se associada as características intrínsecas dos agregados reciclados de concreto que apresentam uma porosidade decorrente da presença de argamassa. As presenças das adições minerais utilizadas nesta pesquisa não afetaram significativamente no desempenho dos concretos, com relação ao módulo de elasticidade, com valores entre 26 e 29 MPa;

- Com relação à absorção de água dos concretos, os produzidos com adição de sílica ativa mostraram-se com sua matriz cimentícia mais densa e, devido a isto, foram os que apresentaram os menores coeficientes de absorção, em especial, para o teor de $10 \%$ da referida adição. Já em relação ao metacaulim, em comparação com a utilização da sílica ativa, os resultados foram inferiores, ou seja, com uma maior absorção de água. Isto, possivelmente, ocorreu devido a microestrutura do material ter possibilitado uma maior interconectividade do meio poroso e, com isso, facilitou o transporte de umidade capilar nas amostras.

- Levando em consideração os resultados inferiores proporcionados pela adição de metacaulim, as sugestões para pesquisas futuras compreendem realizar avaliações em idades superiores para este tipo de material, tendo em vista que seus efeitos podem ser potencializados pelas reações pozolânicas posteriores.

\section{Referências}

Abd elhakam, A., Mohamed, A. E. \& Awad, E. (2012).Influence of self-healing, mixing method and adding silica fume on mechanical properties of recycled aggregates concrete. Construction and building materials, 35, 421-427. Elsevier ltd. <http://dx.doi.org/10.1016/j.conbuildmat.2012.04.013>. .

Associação Brasileira De Normas Técnicas - ABNT (2000). NBR NM 248: Cimento portland e outros materiais em pó - Determinação da massa específica. Rio de janeiro.

Associação Brasileira De Normas Técnicas - ABNT (2007). NBR 5739: Concreto - Ensaio de compressão de corpos-de-prova cilíndricos. 
Associação Brasileira De Normas Técnicas - ABNT (2009). NBR 7211: Agregados para concreto - Especificação.

Associação Brasileira De Normas Técnicas - ABNT (2012). NBR NM 9779: Argamassa e concreto endurecidos - Determinação de absorção de água por capilaridade.

Associação Brasileira De Normas Técnicas - ABNT (2015). NBR 5738: Concreto - Procedimento para moldagem e cura de corpos de prova.

Associação Brasileira De Normas Técnicas - ABNT (2003). NBR NM 248: Agregados - Determinação da composição granulométrica.

Associação Brasileira De Normas Técnicas - ABNT (2003). NBR NM 53: Agregado graúdo - Determinação de massa específica, massa específica aparente e absorção de água.

Associação Brasileira De Normas Técnicas - ABNT (2003). NBR 8522: Concreto - Determinação dos módulos estáticos de elasticidade e de deformação e da curva tensão- deformação.

Associação Brasileira De Normas Técnicas - ABNT (2006). NBR NM 45: Agregados - determinação da massa unitária e do volume de vazios.

Associação Brasileira De Normas Técnicas - ABNT (2009). NBR NM 52: Agregado miúdo - Determinação da massa específica e massa específica aparente.

Behera, M., Bhattacharyya, S. K., Minocha, A. K., Deoliya, R. \& Maiti, S. (2014). Recycled aggregate from c\&d waste \& its use in concrete - a breakthrough towards sustainability in construction sector: a review. Construction And Building Materials, 68, 501-516. Elsevier ltd. <http://dx.doi.org/10.1016/j.conbuildmat.2014.07.003>. .

Berndt, M. L (2009). Properties of sustainable concrete containing fly ash, slag and recycled concrete aggregate. Construction and building materials, v. 23, n. 7, p. 2606-2613. Elsevier ltd. <http://dx.doi.org/10.1016/j.conbuildmat.2009.02.011>. .

Buttler, A. (2003). Concreto com agregados graúdos reciclados de concreto: Influência da idade de reciclagem nas propriedades dos agregados e con cretos reciclados. Dissertação (mestrado em engenharia de estruturas): Escola de Engenharia de São Carlos da Universidade de São Paulo, São Carlos.

Çakir, O. (2014). Experimental analysis of properties of recycled coarse aggregate (RCA) concrete with mineral additives. Construction and Building Materials, $68,17-25$.

Cordeiro, L. N . (2013). Análise dos parâmetros principais que regem a variabilidade de concretos produzidos com agregados graúdos reciclados de concreto. Tese (doutorado em engenharia): Programa de Pós Graduação dm Engenharia Civil da Universidade Federal do Rio Grande do Sul, Porto Alegre.

Corinaldesi, V. \& Moriconi, G. (2009). Influence of mineral additions on the performance of $100 \%$ recycled aggregate concrete. Construction and Building Materials, 23(8), 2869-2876. Elsevier ltd. <http://dx.doi.org/10.1016/j.conbuildmat.2009.02.004>. .

Dilbas, H., Şimşek, M. \& Çakir, Ö. (2014). An investigation on mechanical and physical properties of recycled aggregate concrete (RAC) with and without silica fume. Construction and Building Materials, 61, 50-59. <http://linkinghub.elsevier.com/retrieve/pii/s0950061814002207\nhttp: //www.sciencedirect.com/science/article/pii/s0950061814002207>. .

Helene, P., \& Terzian, P. R. L. (1993). Manual de dosagem e controle do concreto. Pini ed.

Koche, J. C. (2011). Fundamentos de metodologia científica. Petrópolis.

Kou, S. C., Poon, C. S. \& Agrela, F. (2011). Comparisons of natural and recycled aggregate concretes prepared with the addition of different mineral admixtures. Cement and Concrete Composites, 33(8), 788-795. Elsevier ltd. <http://dx.doi.org/10.1016/j.cemconcomp.2011.05.009>.

Leite, M. B. (2001). Avaliação das propriedades mecânicas de concretos produzidos com agregados reciclados de resíduo de construção e demolição. Porto alegre, rs.: Programa de Pós Graduação em Engenharia Civil, Universidade Federal do Rio Grande do Sul, Porto Alegre.

Leite, M. B., Cordeiro, L.N. P., Masuero, A. B. \& Dal Molin, D. C. C. (2011). Proposta de adaptação do procedimento proposto por Leite ( 2001 ) para determinação da absorção de agregados reciclados de resíduo de construção demolição. $7^{\circ}$ Congresso Internacional Sobre Patologia e Reabilitação De Estruturas. Anais.

Limbachiya, M., Meddah, M. S. \& Ouchagour, Y. (2012). Use of recycled concrete aggregate in fly-ash concrete. Construction and Building Materials, 27(1), 439-449. Elsevier ltd. <http://dx.doi.org/10.1016/j.conbuildmat.2011.07.023>.

Mehta, P. K. \& Monteiro, P. J. M. (2014). Concreto: microestrutura, propriedades e materiais.

Neville, A. M. (2016). Propriedades do concreto. (5a ed.), Boo ed.

Radonjanin, V., Malešev, M., Marinković, S. \& Al Malty, A. E. S. (2013). Green recycled aggregate concrete. Construction and Building Materials, 47, 15031511. <http://linkinghub.elsevier.com/retrieve/pii/s0950061813005941>.

Silva, L. R. da, Gama, K. N. de C., Salles, P. V. \& Braga, F. C. S. Concreto com cinza de casca de arroz (CCA) e resíduos de construção e demolição (RCD). Research, Society and Development, 8(4), e2684861, 2019. 10.33448/rsd-v8i4.86: https://rsdjournal.org/index.php/rsd/article/view/861.

Tam, V. W. Y. \& Tam, C. M. (2008). Diversifying two-stage mixing approach (tsma) for recycled aggregate concrete: tsmas and tsmasc. Construction and Building Materials, 22(10), 2068-2077.

Werle, A. N. A. P. Determinação de propriedades de concreto com agregados reciclados de concreto, com ênfase na carbonatação. Dissertação (mestrado em engenharia civil): Programa de Pós Graduação em Engenharia Civil. Universidade do Vale dos Sinos, São Leopoldo. 